\title{
Model for End-Stage Liver Disease (MELD) Exception for Hereditary Hemorrhagic Telangiectasia
}

\author{
Guadalupe Garcia-Tsao, ${ }^{1}$ Robert G. Gish, ${ }^{2}$ and Jeffrey Punch ${ }^{3}$ \\ From ' Yale University School of Medicine, New Haven, CT; ${ }^{2}$ Departments of Medicine and Transplantation \\ and the Division of Hepatology and Complex Gastroenterology, Physicians Foundation, California Pacific \\ Medical Center, San Francisco, CA; and ${ }^{3}$ University of Michigan, Ann Arbor, MI
}

Hereditary hemorrhagic telangiectasia (HHT), also called Rendu-Osler-Weber syndrome, is a rare autosomal dominant disease characterized by arteriovenous malformations involving the skin, mucous membranes, lungs, brain, and gastrointestinal tract. The genetic origin of this disease appears to be a defect in transmembrane proteins that are components of the receptor complex for transforming growth factor- $\beta$ (endoglin, activin receptor like-kinase 1). Hepatic involvement is frequent, but it is asymptomatic in most cases. HHT is characterized by diffuse vascular malformations throughout the liver that result in multiple types of shunting (hepatic artery to hepatic vein, hepatic artery to portal vein, portal vein to hepatic vein), with hepaticartery-to-hepatic-vein shunting being the predominant type.

Symptomatic liver involvement can present as (1) high output cardiac failure (most common presentation), (2) portal hypertension (from hepatic-artery-toportal-vein shunting and/or nodular regenerative hyperplasia), and/or (3) biliary abnormalities such as stricturing and necrosis (probably from ischemia). ${ }^{1} \mathrm{~A}$ patient may have overlapping presentations, and over time, the predominant presentation may transition from one type to another. ${ }^{2}$ Although the diagnosis is not made histologically, the principal features of hepatic HHT are periportal telangiectases with accompanying fibrous tissue and sinusoidal congestion and dilatation. ${ }^{3}$ Liver transplantation (LT) may be indicated in cases of intractable heart failure, biliary sepsis, and intrahepatic hemorrhage. Hereditary hemorrhagic telangiectasia does not appear to progress to cirrhosis, and even though patients may have portal hypertension (with varices and ascites), they generally do not develop liver insufficiency. Diagnosis is made radiographically, most often with an abdominal computed tomography scan demonstrating diffuse heterogenous enhancement of the liver and an enlarged hepatic artery. Histologic examination is unnecessary and may be dangerous.

Liver transplantation for HHT is a difficult procedure. Embolization or operative hepatic artery ligation has been attempted for high-output heart failure; however, experience with these procedures is limited, and results are inconsistent and not durable. ${ }^{4,5}$ More importantly, biliary and liver necrosis leading to acute liver failure have been reported following hepatic artery embolization; therefore, this procedure is not recommended. ${ }^{5}$ Heart failure can be triggered during pregnancy, and spontaneous regression of symptoms after delivery has been reported. ${ }^{6}$

Most published accounts of LT for HHT are singlecase reports. The largest series in the literature, from France, describes 6 patients. ${ }^{1}$ From this experience, in which the median blood loss was 59 units, LT appears to be a difficult procedure due to the hypervascular nature of the liver. Other cases of unsuccessful LT due to fatal intraoperative hemorrhage have been described. The survival rate in this series was $66 \%$, but at least 16 additional patients have been described who received LT for HHT, and all but 1 survived. Hemodynamic studies have indicated that the hyperdynamic state resolves in all cases. Therefore, LT is a reasonably successful option in this setting.

The natural history of hepatic involvement of HHT is unclear. The largest experience, described by GarciaTsao and colleagues, included 19 patients with hepatic HHT. ${ }^{1}$ Eight of the 19 patients had symptomatic high-

Abbreviations: HHT, hereditary hemorrhagic telangiectasia; LT, liver transplantation; MELD, model for end-stage liver disease. Address reprint requests to Robert G. Gish, MD, 2340 Clay St., Room 223, California Pacific Medical Center, San Francisco, CA 94115. Telephone: 415-600-1020 or 415-600-1022; FAX: 415-776-0292; E-mail: gishr@ sutterhealth.org

DOI 10.1002/lt.20978

Published online in Wiley InterScience (www.interscience.wiley.com). 
output cardiac failure. The condition of 3 patients improved, 4 were in stable condition with medical therapy, and 1 died after a median follow-up period of 24 months. Six patients had manifestations of portal hypertension, such as ascites or variceal bleeding. After a median follow-up period of 19 months, the condition of 2 of the 6 patients improved, and the remaining 4 patients died. Five patients had manifestations of biliary disease. After a median follow-up period of 30 months, the condition of 2 of the 5 patients improved, the condition of 1 was unchanged, heart failure developed in 1 , and 1 died after an unsuccessful attempt at LT. From this experience, it appears that progressive disease leading to mortality is frequent but not universal. More recent data show that patients with heart failure who develop biliary ischemia have the highest mortality rate.

\section{SYNTHESIS OF AVAILABLE DATA}

There is insufficient objective evidence to justify automatic additional priority for patients with HHT.

\section{PROPOSAL FOR STANDARDIZED MODEL FOR END-STAGE LIVER DISEASE (MELD) EXCEPTIONS FOR CANDIDATES WITH HHT}

At this time, we propose that patients with HHT continue to be addressed by the regional review boards and additional priority be assigned on a case-by-case basis. Additional priority should not be automatically granted at this time. Our suggestions for the regional boards are to assign a MELD score of 40 to patients with acute biliary necrosis and a MELD score of 22 to patients with intractable heart failure.

\section{INCREMENTAL INCREASES IN MELD SCORE}

If an increased MELD score is provided, the MELD score should increase by an incremental 10\% mortality risk score at 3-month intervals on a case-by-case basis after the regional review board has evaluated all of the information defined above for each 3-month cycle.

\section{REFERENCES}

1. Azoulay D, Precetti S, Emile JF, Ichai P, Gillon MC, Duclos-Vallee JC, et al. Liver transplantation for intrahepatic Rendu-Osler-Weber's disease: the Paul Brousse hospital experience. Gastroenterol Clin Biol 2002;26:828-834.

2. Garcia-Tsao G, Korzenik JR, Young L, Henderson KJ, Jain D, Byrd B, et al. Liver disease in patients with hereditary hemorrhagic telangiectasia. N Engl J Med 2000;343:931936.

3. Blewitt RW, Brown CM, Wyatt JI. The pathology of acute hepatic disintegration in hereditary haemorrhagic telangiectasia. Histopathology 2003;42:265-269.

4. Neumann UP, Knoop M, Langrehr JM, Keck H, Bechstein WO, Lobeck H, et al. Effective therapy for hepatic M. Osler with systemic hypercirculation by ligation of the hepatic artery and subsequent liver transplantation. Transpl Int 1998;11:323-326.

5. Odorico JS, Hakim MN, Becker YT, Van Der WW, Musat A, Knechtle SJ, et al. Liver transplantation as definitive therapy for complications after arterial embolization for hepatic manifestations of hereditary hemorrhagic telangiectasia. Liver Transpl Surg 1998;4:483-490.

6. Livneh A, Langevitz P, Morag B, Catania A, Pras M. Functionally reversible hepatic arteriovenous fistulas during pregnancy in patients with hereditary hemorrhagic telangiectasia. South Med J 1988;81:1047-1049. 